Pacific Journal of Mathematics

INTEGRAL CLOSURE OF RINGS OF SOLUTIONS OF LINEAR 


\title{
INTEGRAL CLOSURE OF RINGS OF SOLUTIONS OF LINEAR DIFFERENTIAL EQUATIONS
}

\author{
EdWARd C. Posner
}

Let $K$ be an ordiary differential field of characteristic zero with field of constants $C$. Let $R$ be a differential subring of $K$ containing $C$ and having quotient field $K$. A differential subring $V$ of an extension differential field $M$ of $K$ is called a fundamental differential ring (over $R$ ) if $V$ contains $R$ and if, for each $v$ in $V$, there exist $v_{2}, \cdots, v_{n}$ in $V, n$ depending on $v$, such that $v, v_{2}, \cdots, v_{n}$ form a fundamental system of solutions of a homogeneous linear differential equation with coefficients in $K$. Throughout this paper, $\{\cdots\}$ denotes differential ring adjunction, $\langle\cdots\rangle$ differential field adjunction.

Theorem 1. Let $K, C, R, M, V$ be as above. Then $V$ is a fundamental differential ring over $R$ if and only if $V=R\left\{v_{\alpha i}, \alpha \in A, 1 \leqq i\right.$ $\left.\leqq n_{\alpha}\right\}, A$ an indexing set, where for each $\alpha$ in $A, v_{\alpha 1}, v_{\alpha_{2}}, \cdots, v_{\alpha_{a}}$ form a fundamental system of solutions of a homogeneous linear differential equation over $K$.

Proof. If $V$ is a fundamental differential ring over $R$, we may let $A=V$; the interest attaches to the converse. It amounts to proving that every differential polynomial with coefficients in $R$ in the $v_{\alpha i}$ is one element of a fundamental system of solutions of a homogeneous linear differential equation over $K$, all the elements of which system of solutions belong to $V$. By use of induction, we may reduce the problem to consideration of the four differential polynomials $s^{\prime}, s+t, s t$, and $r s$, $r \in K$. We treat the polynomials $s^{\prime}$ and $s+t$; the polynomials st and $r s$ are treated in a like manner.

Let $s^{(n)}+a_{n-1} s^{(n-1)}+\cdots+a_{0} s=0, a_{i} \in K, 0 \leqq i \leqq n-1$. (There is no loss of generality in supposing that the leading coefficient of this differential equation is 1.) If $a_{0}=0$, then $s^{\prime}$ already satisfies a homogeneous linear differential equation (of order $n-1$ ) over $K$; if $a_{0} \neq 0$, we differentiate the expression

$$
\left(\left(\frac{1}{a_{0}}\right) s^{(n)}+\left(\frac{a_{n-1}}{a_{0}}\right) s^{(n-1)}+\cdots+\left(\frac{a_{1}}{a_{0}}\right) s^{\prime}+s\right)
$$

to obtain a homogeneous linear differential equation of order $n$ in $s^{\prime}$

Received May 23, 1960, and in revised form February 8, 1962. Supported by NASA Contract NASw- 6 between the Jet Propulsion Laboratory of the California Institute of Technology and the National Aeronautics and Space Administration. I am indebted to the referee for suggesting valuable improvements incorporated into this paper. 
with coefficients in $K$.

To prove the result for $s+t$, let $s, t$ be in $V$ with $s+t \neq 0$; let $s, s_{2}, \cdots, s_{n}$ be $n$ elements of $V$ forming a fundamental system of solutions of a homogeneous linear differential equation over $K$, and the same for $t, t_{2}, \cdots, t_{m}$. Let $s_{1}=s, t_{1}=t$. Let $u_{1}=s_{1}+t_{1}$ and choose $u_{2}, u_{3}, \cdots, u_{r}$ from among $s_{1}, s_{2}, \cdots, s_{n} ; t_{1}, t_{2}, \cdots, t_{m}$ such that $u_{1}, u_{2}, \cdots$, $u_{r}$ form a basis over the constants for the vector space spanned over the constants by $s_{1}, s_{2}, \cdots, s_{n} ; t_{1}, t_{2}, \cdots, t_{m}$. Let $W\left(z_{1}, z_{2}, \cdots, z_{p}\right)$ denote the wronskian of the $p$ elements $z_{1}, z_{2}, \cdots, z_{p}$. Consider the linear differential operator of order $r, \mathscr{L}(y)=W\left(y, u_{1}, \cdots, u_{r}\right) / W\left(u_{1}, \cdots, u_{r}\right)$. (Since $u_{1}, \cdots, u_{r}$ are linearly independent over constants, their wronskian is nonzero.) $\mathscr{L}\left(u_{r}\right)=0,1 \leqq \lambda \leqq r$, and $\mathscr{L} \neq 0$ since the coefficient of $y^{(r)}$ is $1=W\left(u_{1}, \cdots, u_{r}\right) / W\left(u_{1}, \cdots, u_{r}\right)$. We shall prove that all the coefficients of $\mathscr{L}$ are in $K ; \mathscr{L}(y)=0$ will then be the sought-after differential equation.

Let $\sigma$ be a differential isomorphism of $K\left\langle s_{1}, s_{2}, \cdots, s_{n} ; t_{1}, t_{2}, \cdots, t_{m}\right\rangle$ over $K$; then $\sigma\left(s_{\mu}\right)=\sum_{i=1}^{n} c_{\mu i} s_{i}, 1 \leqq \mu \leqq n$ and $\sigma\left(t_{\nu}\right) \sum_{j=1}^{m} d_{\nu j} t_{j}, 1 \leqq \nu \leqq m$, where the $c_{\mu i}$ and $d_{\nu j}$ are constants. This is true because $s_{1}, s_{2}, \cdots, s_{n}$ span over constants the vector space of solutions of the homogeneous linear differential equation over $K$ satisfied by $s_{1}$; similarly for $t_{1}, \cdots$, $t_{m}$. These two sets of equations taken together imply $\sigma\left(u_{\lambda}\right)=\sum_{k=1}^{r}$ $e_{\lambda k} u_{k}, 1 \leqq \lambda \leqq r, e_{\lambda k}$ constants, for each $\sigma\left(u_{\lambda}\right)$ is in the vector space spanned over the constants by $s_{1}, \cdots, s_{n} ; t_{1}, \cdots, t_{m}$.

This implies that $W\left(y, \sigma u_{1}, \cdots, \sigma u_{r}\right)=\left(\operatorname{det}\left(e_{\lambda_{k}}\right)\right) W\left(y, u_{1}, \cdots, u_{r}\right)$, and similarly $W\left(\sigma u_{1}, \cdots, \sigma u_{r}\right)=\left(\operatorname{det}\left(e_{\lambda_{k}}\right)\right) W\left(u_{1}, \cdots, u_{r}\right)$. Therefore the coefficients $a_{p}, 0 \leqq p \leqq r$, of $\mathscr{L}(y)$ are invariant under $\sigma$, for all differential isomorphisms $\sigma$ of $K\left\langle s_{1}, \cdots, s_{n} ; t_{1}, \cdots, t_{m}\right\rangle$ over $K$. By Theorem 2.6, pg. 16 of [1], $a_{p}$ is in $K$, as required. This proves the theorem.

The above theorem has the following immediate consequence.

CoRollary. If $M$ is a universal differential field extension of $K$ ([2], Sec. 5, esp. pg. 771, Theorem), the set $V$ of all elements of $M$ satisfying a homogeneous linear differential equation over $K$ forms a fundamental differential ring.

The following lemma isolates the key property of fundamental differential rings that will be used to prove integral closure. An element $w$ in an extension differential field of $K$ is called a wronskian over $K$ if $w \neq 0$ and $w^{\prime} / w$ belongs to $K$.

Lemma. Let $V$ be a fundamental differential ring over $R$. Then any nonzero differential ideal $I$ of $V$ contains a wronskian over $K$. 
Proof. Let $u_{1}$ be a nonzero element of the differential ideal $I$ of $V$, and let $u_{2}, u_{3}, \cdots, u_{n}$ be $n-1$ elements of $V$ such that $u_{1}, u_{2}, \cdots$, $u_{n}$ form a fundamental system of solutions of a homogeneous linear differential equation over $K$. Then $W\left(u_{1}, u_{2}, \cdots, u_{n}\right)$ is a nonzero element of $I$ : it is nonzero since $u_{1}, u_{2}, \cdots, u_{n}$ are linearly independent over constants; it belongs to $I$ because each term in the expansion of the determinant defining $W\left(u_{1}, \cdots, u_{n}\right)$ contains a derivative of $u_{1}$ as a factor. Since $W\left(u_{1}, \cdots, u_{n}\right)$ is a wronskian over $K$, the proof is complete.

Definition. A differential ring is called differentiably simple if it has no differential ideals other than zero and itself.

THeOREM 2. Let $R$ be differentiably simple (in particular, $R=$ $K)$, and for every wronskian $w$ over $K$ belonging to $V$, let there exist a nonzero $h$ in $R$ such that $h / w$ is in $V$. Then $V$ too is differentiably simple. (When $R=K$, the assumption is that $V$ contains the inverse of every wronskian over $K$ which belongs to $V$.)

Proof. Let $I$ be a nonzero differential ideal of $V$. To prove that $I=V$, let be a wronskian over $K$ in $I$; such exist by the lemma. Now by hypothesis, there is a nonzero $h$ in $R$ with $h / w$ in $V$. Thus $w \cdot h / w=h$ is in $I$, so that $I \cap R$ is not the zero ideal of $R$. Since $I \cap R$ is a differential ideal of $R$ and $R$ is differentiably simple, $I \cap R$ $=R$, so that $1 \in I \cap R$, and $1 \in I$. Thus $I=V$ as required.

The next theorem is a sort of converse to the previous theorem. (Here $V$ need not be a fundamental differential ring over $R ; V$ can be any differential subring of $M$ containing $R$.)

THEOREM 3. Let $V$, but not necessarily $R$, be differentiably simple, and let $w$ be a wronskian over $K$ belonging to $V$. Then there is a nonzero $h$ in $R$ such that $h / w$ is in $V$. (Thus if $R=K, 1 / w$ is in $V$.)

Proof. Since $K$ is the quotient field of $R$, there exist $b, c$ in $R$, with $c \neq 0$, such that $w^{\prime}=(b / c) w$. Let $I$ denote the set of elements of $V$ of the form $v c^{-p} w, p$ a nonnegative integer, $v$ an element of $V$. $I$ can readily be shown to be an ideal of $V$; we shall prove that $I$ is closed under differentiation. If $v c^{-p} w \in I$, then $\left(v c^{-p} w\right)^{\prime}=v^{\prime} c^{-p} w-$ $p v c^{-p-1} c^{\prime} w+v c^{-p} w^{\prime}=\left(v^{\prime} c\right) c^{-p-1} w-\left(p v c^{\prime}\right) c^{-p-1} w+(b v) c^{-p-1} w=\left(v^{\prime} c-p v c^{\prime}\right.$ $+b v) c^{-p-1} w$ is an element of $V$ and hence of $I$. Thus $I$ is a differential ideal of $V$, and is nonzero since $w$ is in $I$. Since $V$ is differentiably simple, $I=V$, and $1 \in I$. Thus $1=v c^{-p} w$ for some $v \in V, p \geqq 0$. Then, if $c^{p}=h$, we have $h / w=v \in V$, with $h$ an element of $R$. This proves the theorem. 
The following theorem with $K=C$ generalizes a consequence of a result of Ritt ([4], Sec. 1, pg. 681) to the effect that if $C$ is the field of complex numbers, the ring $C\left[e^{\lambda x}\right.$, all complex $\left.\lambda\right]$ is integrally closed in its quotient field. In fact, Theorem 4 also implies that $C\left[x, e^{\lambda x}\right]$ is is integrally closed in its quotient field.

THEOREM 4. Let $K$ be a differential field of characteristic zero with field of constants $C$. Let $K$ be differential algebraic over $C$. Let $V$ be a fundamental differential ring over $K$ which contains the inverse of every wronskian over $K$ in it. Then $V$ is integrally closed in its quotient field (it is differentiably simple by Theorem 2).

Proof. Let $u$ be an element of the quotient field $M$ of $V$ integral over $V$ : that is, there exist elements $v_{i}$ in $V, 1 \leqq i \leqq n$, such that $u^{n}+\sum_{i=1}^{n} v_{i} u^{n-i}=0$, and there exist $v_{n+1}, v_{n+2}$ in $V$ with $u=v_{n+1} / v_{n+2}$. Let $v_{i}$ be a solution of a homogeneous linear differential equation $\mathscr{L}_{i}(y)$ $=0,1 \leqq i \leqq n+2$, where $\mathscr{L}_{i}(y)=\sum_{j=0}^{n i} b_{i j} y^{(j)}, 1 \leqq i \leqq n+2,0 \leqq j \leqq$ $n_{i} ; b_{i n_{i}}=1,1 \leqq i \leqq n+2$. Furthermore let $v_{i k}, 1 \leqq k \leqq n_{i}$, be for each $i$ a fundamntal system of solutions of $\mathscr{L}_{i}(y)=0$, with $v_{i 1}=v_{i}$. Let $Y$ be a differential indeterminate, and, for each $i, j$, let $P_{i j}(Y) \in C\{Y\}$ be a differential polynomial of lowest order $r_{i j}$ say satisfied by $b_{i j}$ over $C$ and such that the degree of $P_{i j}$ in $Y^{\left(r_{i j}\right)}$ is as small as possible among these differential polynomials of order $r_{i j}$. Define the separant $S_{i j}$ of $P_{i j}$ as the (partial) derivative of $P_{i j}$ with respect to $Y^{\left(r_{i j}\right)}$. One verifies, using the minimal property of the $P_{i j}$, that $S_{i j}\left(b_{i j}\right)$ is nonzero. Then $b_{i j}^{\left(r_{i j}+1\right)}$ is $S_{i j}^{-1}\left(b_{i j}\right)$ multiplied by a differential polynomial over $C$ in $b_{i j}$ of order at most $r_{i j}$. This implies that $C\left\{b_{i j}\right\}=C\left[b_{i j}^{(p)}, 0 \leqq p \leqq r_{i j}\right]$, all $i, j$. (This argument is well known.)

Now define $\bar{V}=C\left\{b_{i j}, S_{i j}^{-1}\left(v_{i j}\right), v_{i k}\right.$, all $1 \leqq i \leqq n+2,0 \leqq j \leqq n_{i}$, $\left.1 \leqq k \leqq n_{i}\right\}$; observe $\bar{V} \subset V$. Since $\mathscr{L}_{i}$ has leading coefficient 1 and $\mathscr{L}_{i}\left(v_{i k}\right)=0,1 \leqq i \leqq n+2,1 \leqq k \leqq n_{i}$, and because of the above property of each $C\left\{b_{i j}\right\}$, one concludes that $\bar{V}=C\left[b_{i j}^{(p)}, S_{i j}^{-1}\left(b_{i j}\right), v_{i k}^{(q)}\right.$, all $\left.1 \leqq i \leqq n+2,0 \leqq \dddot{j} \leqq n_{i}, 1 \leqq k \leqq n_{i} 0 \leqq p \leqq r_{i j}, 0 \leqq q \leqq n_{i}-1\right]$. This is what we were after: we have proved that $\bar{V}$ is finitely generated as an ordinary ring over $C$. We can now apply Theorem 2 of [3] to conclude that the integral closure $\bar{O}$ of $\bar{V}$ in its quotient field $\bar{M}$ is in fact a differential subring of $\bar{M}$. But $u$ is in $\bar{O}$; if we can prove that $\bar{O}$ is contained in $\bar{V}$, the proof will be completed.

So consider the ideal $\bar{I}$ of $\bar{V}$ consisting of all $h$ in $\bar{V}$ such that $h \bar{O} \subset \bar{V}$. By [5], pg. 267, Theorem 9, $\bar{I}$ is nonzero; a fortiori, the ideal $I$ of $V$ consisting of those $h$ in $V$ with $h \bar{O} \subset V$ is also nonzero, since it contains $\bar{I}$. We assert that $I$ is a differential ideal of $V$ : let $\omega \in \bar{O}$; then $h \omega \in V,(h \omega)^{\prime}=h^{\prime} \omega+h \omega^{\prime} \in V$. Since $\bar{O}$ is closed under differentiation by [3], pg. 1393, lemma, $\omega^{\prime} \in \bar{O}$, so that, since $h \in I$, 
$h \omega^{\prime} \in V$. Thus $h^{\prime} \omega$ is in $V$ if $\omega$ is in $\bar{O}$ and $h$ is in $I$. In other words, $I$ is a differential ideal of $V$. Since $V$ is differentiably simple by Theorem 2 , and $I$ is nonzero, we conclude that $I=V$. Therefore $1 \in I$. This implies that $\bar{O}=1 \cdot \bar{O}$ is contained in $V$, as promised. This completes the proof of Theorem 4 .

(The above theorem could be strengthened by use of the following unproved result: a differentiably simple ring of characteristic zero is integrally closed in its quotient field. This result would generalize Theorem 1 of [3].)

Theorem 4 has the following corollary.

CoRollary. Let $K$ be a differential field of characterististic zero with field of constants $C$. Let $K$ be differential algebraic over $C$. Let $M$ be a universal differential field extension of $K$. Let $V$ be the subset of $M$ comprising those elements of $M$ satisfying a homogeneous linear differential equation over $K$. Then $V$ is integrally closed in its quotient field.

Proof. That $V$ is a fundamental differential ring over $K$ follows from the corollary to Theorem 1 . To prove $V$ integrally closed in its quotient field, we shall prove that $V$ contains the inverse of every wronskian over $K$ in it, and then apply Theorem 4 .

Now if $w$ is a wronskian over $K$ in $V$, then $w \neq 0$ and $w^{\prime}=k w$, $k \in K$. Then $(1 / w)^{\prime}=\left(-1 / w^{2}\right) \cdot w^{\prime}=\left(-1 / w^{2}\right) \cdot k w=-k \cdot(1 / w)$. So $1 / w$ satisfies a (first order) homogeneous linear differential equation over $K$; by the definition of $V,(1 / w)$ belongs to $V$, as required for the application of Theorem 4 .

REMARK. Let $V_{1}=V$ and $V_{n+1}, n \geqq 1$, be the differential subring of $M$ consisting of those elements of $M$ satisfying a homegeneous linear differential equation with coefficients in $V_{n}$. Then $V_{n+1}$ contains $L_{n}$ (thus $\mathrm{U}_{n=1}^{\infty} V_{n}=V_{\infty}$ is a field), for if $f(\neq 0)$ is in $V_{n}$, then $(1 / f)^{\prime}=$ $-f^{\prime} \mid f \cdot 1 / f$. Thus $1 / f$ satisfies a first order homogeneous linear differential equation with coefficients in $L_{n}$ and so is in $V_{n+1}$. Since $V_{n+1}$ contains $V_{n}$, and now the inverse of every nonzero element in $V_{n}, V_{n+1}$ contains $L_{n}$. But each $L_{n}$ is differential algebraic over $C$, and $M$ is still a universal differential extension of $L_{n}$. The above corollary thus implies that each $V_{n}$ is integrally closed in its quotient field $L_{n}, n \geqq 1$.

\section{BIBLIOGRAPHY}

1. I. Kaplansky, An Introduction to Differential Algebra, Paris, Hermann, 1957.

2. E. R. Kolchin, Galois theory of differential fields, Amer. J. of Math., 75 (1953), 753-824. 
3. E. C. Posner, Integral closure of differential rings, Pacific J. Math., 10 (1960), 13931396.

4. J. F. Ritt, On the zeros af exponential polynomials, Trans. Amer. Math. Soc., 52 (1928), 680-686.

5. O. Zariski, and P. Samuel, Commutative Algebra, Vol. I, Princeton, van Nostrand, 1958. CALIFornia InStitute of TechNology 


\section{PACIFIC JOURNAL OF MATHEMATICS}

\section{EDITORS}

\author{
Ralph S. Phillips \\ Stanford University \\ Stanford, California \\ M. G. Arsove \\ University of Washington \\ Seattle 5 , Washington
}

\author{
A. L. Whiteman \\ University of Southern California \\ Los Angeles 7, California \\ Lowell J. Paige \\ University of California \\ Los Angeles 24, California
}
E. F. BECKENBACH
D. DERRY
ASSOCIATE EDITORS
T. M. CHERRY
M. OHTSUKA
H. L. ROYDEN
E. G. STRAUS
E. SPANIER
F. WOLF

\section{SUPPORTING INSTITUTIONS}

\author{
UNIVERSITY OF BRITISH COLUMBIA \\ CALIFORNIA INSTITUTE OF TECHNOLOGY \\ UNIVERSITY OF CALIFORNIA \\ MONTANA STATE UNIVERSITY \\ UNIVERSITY OF NEVADA \\ NEW MEXICO STATE UNIVERSITY \\ OREGON STATE UNIVERSITY \\ UNIVERSITY OF OREGON \\ OSAKA UNIVERSITY \\ UNIVERSITY OF SOUTHERN CALIFORNIA
}

\author{
STANFORD UNIVERSITY \\ UNIVERSITY OF TOKYO \\ UNIVERSITY OF UTAH \\ WASHINGTON STATE UNIVERSITY \\ UNIVERSITY OF WASHINGTON \\ AMERICAN MATHEMATICAL SOCIETY \\ CALIFORNIA RESEARCH CORPORATION \\ SPACE TECHNOLOGY LABORATORIES \\ NAVAL ORDNANCE TEST STATION
}

Mathematical papers intended for publication in the Pacific Journal of Mathematıcs should be typewritten (double spaced), and the author should keep a complete copy. Manuscripts may be sent to any one of the four editors. All other communications to the editors should be addressed to the managing editor, L. J. Paige at the University of California, Los Angeles 24, California.

50 reprints per author of each article are furnished free of charge; additional copies may be obtained at cost in multiples of 50 .

The Pacific Journal of Mathematics is published quarterly, in March, June, September, and December. Effective with Volume 13 the price per volume (4 numbers) is $\$ 18.00$; single issues, $\$ 5.00$. Special price for current issues to individual faculty members of supporting institutions and to individual members of the American Mathematical Society: $\$ 8.00$ per volume; single issues $\$ 2.50$. Back numbers are available.

Subscriptions, orders for back numbers, and changes of address should be sent to Pacific Journal of Mathematics, 103 Highland Boulevard, Berkeley 8, California.

Printed at Kokusai Bunken Insatsusha (International Academic Printing Co., Ltd.), No. 6, 2-chome, Fujimi-cho, Chiyoda-ku, Tokyo, Japan.

PUBLISHED BY PACIFIC JOURNAL OF MATHEMATICS, A NON-PROFIT CORPORATION

The Supporting Institutions listed above contribute to the cost of publication of this Journal, but they are not owners or publishers and have no responsibility for its content or policies. 


\section{Pacific Journal of Mathematics}

\section{Vol. 12 , No. 4 \\ April, 1962}

Tsuyoshi Andô, On fundamental properties of a Banach space with a cone ..... . 1163

Sterling K. Berberian, A note on hyponormal operators ................ 1171

Errett Albert Bishop, Analytic functions with values in a Frechet space . . . . . . . 1177

(Sherman) Elwood Bohn, Equicontinuity of solutions of a quasi-linear equation ............................................ 1193

Andrew Michael Bruckner and E. Ostrow, Some function classes related to the class of convex functions . . . . . . . . . . . . . . . . . . . . . . . . 1203

J. H. Curtiss, Limits and bounds for divided differences on a Jordan curve in the complex domain . . ................................. 1217

P. H. Doyle, III and John Gilbert Hocking, Dimensional invertibility . . . . . . . . 1235

David G. Feingold and Richard Steven Varga, Block diagonally dominant matrices and generalizations of the Gerschgorin circle theorem ................. 1241

Leonard Dubois Fountain and Lloyd Kenneth Jackson, A generalized solution of the boundary value problem for $y^{\prime \prime}=f\left(x, y, y^{\prime}\right) \ldots \ldots \ldots \ldots \ldots \ldots \ldots \ldots \ldots$

Robert William Gilmer, Jr., Rings in which semi-primary ideals are primary. . . . . 1273

Ruth Goodman, K-polar polynomials .......................... 1277

Israel Halperin and Maria Wonenburger, On the additivity of lattice completeness ........................................... 1289

Robert Winship Heath, Arc-wise connectedness in semi-metric spaces . . . . . . . . 1301

Isidore Heller and Alan Jerome Hoffman, On unimodular matrices . . . . . . . . . . . 1321

Robert G. Heyneman, Duality in general ergodic theory . . . . . . . . . . . . . . . 1329

Charles Ray Hobby, Abelian subgroups of p-groups . . . . . . . . . . . . . . . 1343

Kenneth Myron Hoffman and Hugo Rossi, The minimum boundary for an analytic

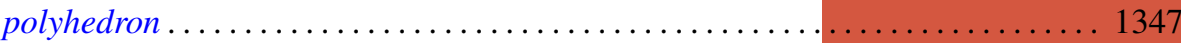

Adam Koranyi, The Bergman kernel function for tubes over convex cones ........ 1355

Pesi Rustom Masani and Jack Max Robertson, The time-domain analysis of a continuous parameter weakly stationary stochastic proces.

William Schumacher Massey, Non-existence of almost-complex structures on

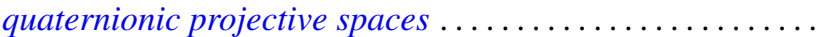

Deane Montgomery and Chung-Tao Yang, A theorem on the action of $\mathrm{SO}(3) \ldots . .1385$

Ronald John Nunke, A note on Abelian group extensions . . . . . . . . . . . . . 1401

Carl Mark Pearcy, A complete set of unitary invariants for operators generating finite $W^{*}$-algebras of type $I$

Edward C. Posner, Integral closure of rings of solutions of linear differential equations.

Duane Sather, Asymptotics. III. Stationary phase for two parameters with an application to Bessel functions.

J. Śladkowska, Bounds of analytic functions of two complex variables in domains

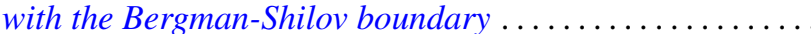

Joseph Gail Stampfli, Hyponormal operators .

George Gustave Weill, Some extremal properties of linear combinations of kernels

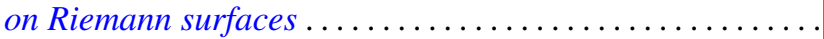

